
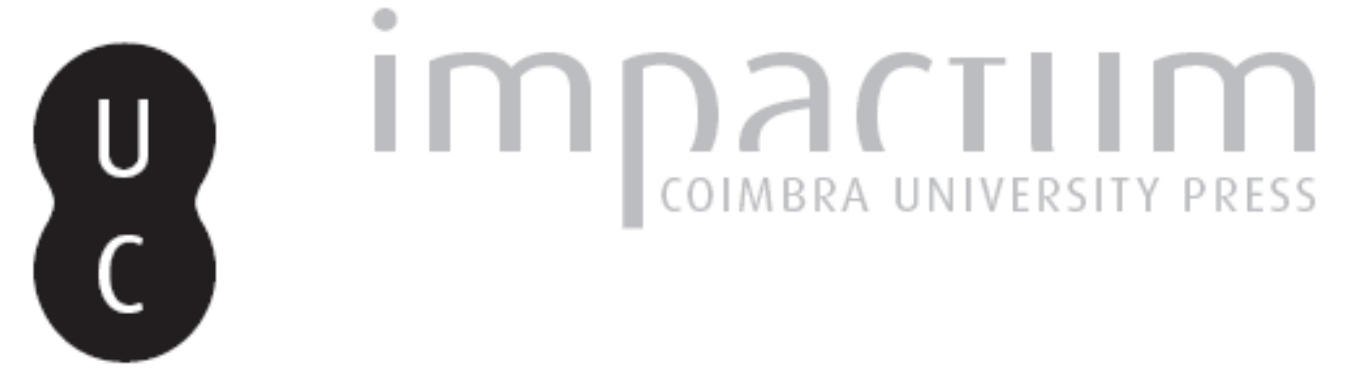

\title{
Linha de Cascais: muito mais do que uma via-férrea turística, um estímulo à concentração populacional na faixa costeira por ela servida (1911-1944)
}

Autor(es): $\quad$ Paulino, Joana Catarina Vieira

Publicado por: Centro de História da Sociedade e da Cultura

URL persistente:

URl:http://hdl.handle.net/10316.2/39398

DOI:

DOI:http://dx.doi.org/10.14195/1645-2259_13_16

Accessed : $\quad$ 26-Apr-2023 01:07:19

A navegação consulta e descarregamento dos títulos inseridos nas Bibliotecas Digitais UC Digitalis, UC Pombalina e UC Impactum, pressupõem a aceitação plena e sem reservas dos Termos e Condições de Uso destas Bibliotecas Digitais, disponíveis em https://digitalis.uc.pt/pt-pt/termos.

Conforme exposto nos referidos Termos e Condições de Uso, o descarregamento de títulos de acesso restrito requer uma licença válida de autorização devendo o utilizador aceder ao(s) documento(s) a partir de um endereço de IP da instituição detentora da supramencionada licença.

Ao utilizador é apenas permitido o descarregamento para uso pessoal, pelo que o emprego do(s) título(s) descarregado(s) para outro fim, designadamente comercial, carece de autorização do respetivo autor ou editor da obra.

Na medida em que todas as obras da UC Digitalis se encontram protegidas pelo Código do Direito de Autor e Direitos Conexos e demais legislação aplicável, toda a cópia, parcial ou total, deste documento, nos casos em que é legalmente admitida, deverá conter ou fazer-se acompanhar por este aviso.

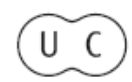



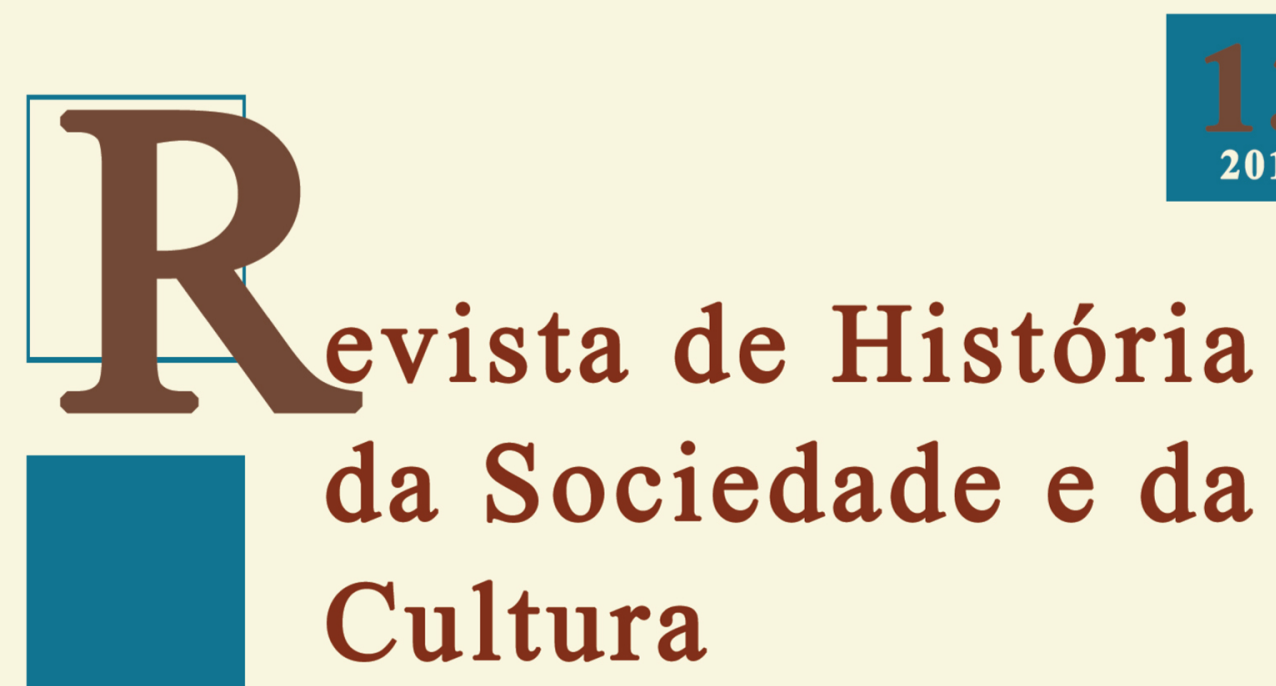

2013

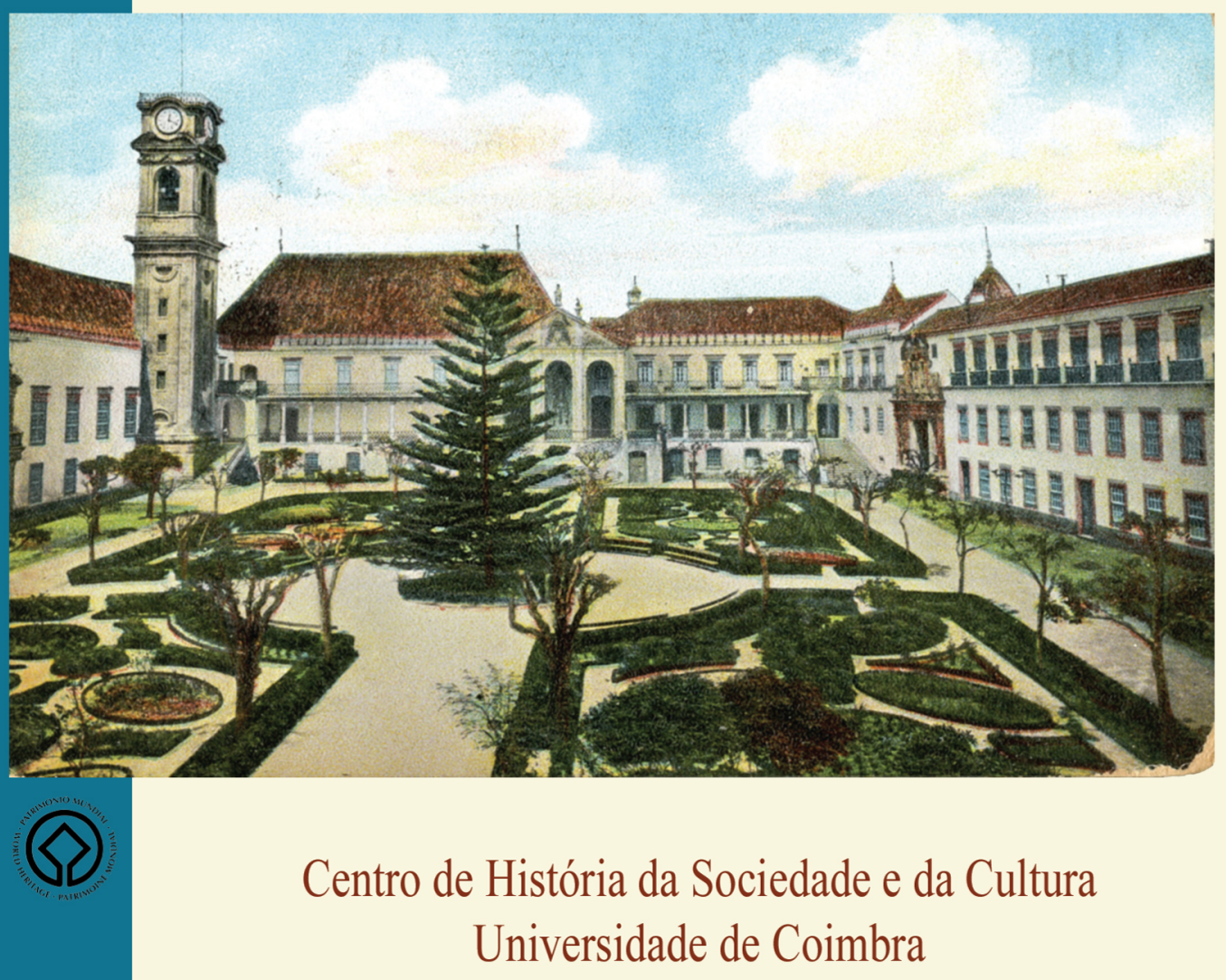

Coimbra 


\title{
Linha de Cascais: muito mais do que uma via-férrea turística, um estímulo à concentração populacional na faixa costeira por ela servida (1911-1944)*
}

\author{
Joana Catarina Vieira Paulino \\ Instituto de História Contemporânea - Faculdade de Ciências Sociais e Humanas da \\ Universidade Nova de Lisboa \\ joana_paulino40@hotmail.com \\ Texto recebido em /Text submitted on: 30/05/2013 \\ Texto aprovado em /Text approved on: 22/10/2013
}

\section{Resumo/Abstract:}

A linha de Cascais, construída no final do século XIX e tendo, inicialmente, um fito turístico, de veraneio e prática de banhos, acabou por se revelar uma via-férrea que promoveu a concentração de população de facto no espaço suburbano e rural por ela servido, nomeadamente, entre Algés e Cascais. Cabe, neste estudo, verificar: qual o alcance da influência do caminho-de-ferro; quais as povoações que, em termos demográficos, se destacavam e se estas já tinham alguma importância anterior, em termos de quantitativos populacionais e sectores de actividade a elas associados; e, para finalizar, qual o carácter de ocupação da faixa costeira pela população, nomeadamente, se é contínuo ou descontínuo. Visa-se, assim, à luz da presença do caminho-de-ferro (e, nos anos 20 do século XX, mediante a sua electrificação, que constituiu um estímulo e um factor atractivo), estudar o processo de suburbanização da cidade de Lisboa para Oeste, junto à zona ribeirinha, o qual, alguns anos mais tarde, originou a formação de parte integrante da Área Metropolitana de Lisboa.

Cascais railway, built in the end of the $19^{\text {th }}$ century and initially having a touristic and sea bathing propose, turned out to be a railway that promoted population's concentration in the suburban and rural areas where it passed by, mainly, between Algés and Cascais. In this study we want to verify: the influence's scope of the railway; which were, in a demographic analysis, the most important settlements and if they already had an earlier importance related to demographic quantitatives and to the presence of a certain activity; and, to finish, what was the character of coast's occupation by the population, namely, if it was continuous or not. It is intended, therefore, through the presence of the railway (and, in the twenties of $20^{\text {th }}$ century, considering its electrification, which made it a lot more attractive), to study Lisbon's suburbanization process to the West, by the coast, a space that, a few years later, integrated Lisbon's Metropolitan Area.

Palavras chave/Keywords:

História Contemporânea; História Urbana; Linha de Cascais; Suburbanização; Turismo.

Contemporary History; Urban History; Cascais Railway; Suburbanization; Tourism.

* O presente estudo resulta da adaptação do terceiro capítulo da minha Dissertação de Mestrado, defendida em Janeiro de 2013 na Faculdade de Ciências Sociais e Humanas da Universidade de Lisboa-PAULINO, Joana, A linha de Cascais: construção e modernização. Reflexos no turismo e no processo de suburbanização da cidade de Lisboa. Lisboa: F.C.S.H.-U.N.L., 2013. 
O fito de construção da linha de caminho-de-ferro que vai do Cais do Sodré a Cascais residiu no turismo, um sector económico emergente no século XIX. No que concerne à faixa costeira em estudo, tal encontra-se relacionado com o crescente gosto pelos banhos de mar, pelas praias e, num sentido mais abrangente, pela prática de vilegiatura.

Este objectivo de edificação subjacente ajuda a justificar a forma parcelar como a linha de Cascais foi construída e inaugurada pela sua concessionária, a Companhia Real dos Caminhos de Ferro Portugueses - em Setembro de 1889 foi aberto o troço entre Pedrouços e Cascais, respondendo ao apelo dos banhos de mar e do gosto pela vilegiatura. O próprio monarca, D. Luís (1838-1889, reinado: 1861-1889), compreendeu a necessidade de existência do caminho-de-ferro para o desenvolvimento turístico de toda a zona ribeirinha (e não apenas da vila de Cascais) motivo pelo qual, a título de exemplo, exigiu passagens de nível superiores e inferiores para o serviço das praias, tantas quanto necessárias. ${ }^{1}$ Por sua vez, o troço urbano entre Pedrouços e Alcântara-Mar só viria a ser inaugurado em 1891 e, o segmento entre esta última estação e o Cais do Sodré, em $1895 .^{2}$

Contudo, não descurando a importância que a linha de Cascais teve para o desenvolvimento turístico do espaço costeiro e que constituiu o mote para a sua construção, sobretudo, a partir de 1895, com a chegada do caminho-de-ferro ao epicentro da cidade, esta tornou-se numa via de forte movimento intra-urbano. Tal tendência só culminou com a consolidação do eléctrico da Companhia Carris de Ferro de Lisboa, inaugurado em 1901, como meio de transporte concorrencial e preferencial ao caminho-de-ferro no trajecto urbano até Algés. A partir de então, a linha de Cascais começou a perder o seu pendor citadino, ascendendo a importância do tráfego rural, nomeadamente, da cidade para as estações das povoações suburbanas e rurais e entre estas últimas.

Cabe, antes de mais e como ponto de partida, atestar, no que concerne à linha de Cascais, o que é considerado espaço urbano e espaço rural, uma

1 Arquivo Histórico e Fotográfico da Comboios de Portugal (Lisboa), Carta de D. Luís I à C.R.C.F.P. aprovando o projecto de 2 de Julho de 1887, fl. 1.

2 A Companhia Real dos Caminhos de Ferro Portugueses tornou-se concessionária da construção e exploração da linha de caminho-de-ferro de Cascais por alvará régio de 9 de Abril de 1887. 
vez que a via-férrea em estudo serve cerca de 25 quilómetros junto ao rio Tejo, albergando esta «duplicidade». Assim, deve-se definir, de acordo com a divisão administrativa de 1940, a zona urbana, que vai do Cais do Sodré a Pedrouços, por estar inserida no concelho de Lisboa e, a zona rural, que vai de Algés a Cascais, enquadrada nos concelhos de Oeiras e Cascais. Não se deve esquecer, no entanto, que a zona rural abrange uma área que, pela sua proximidade e relação directa com a cidade é considerada suburbana. Trata-se das povoações de Algés, Dafundo e Cruz Quebrada, questão que será aprofundada a posteriori. ${ }^{3}$

Assim, o que se pretende neste estudo é, partindo da ideia de predomínio do tráfego suburbano e rural, entre Algés e Cascais, atestar a relação entre a presença do caminho-de-ferro e o crescimento da população de facto nas povoações enquadradas nesta parcela de costa, no período censitário compreendido entre 1911-1940. ${ }^{4}$ Poder-se-á falar de uma suburbanização da cidade de Lisboa para Oeste, junto à zona ribeirinha que daria origem, alguns anos mais tarde, a parte integrante da Área Metropolitana de Lisboa? ${ }^{5}$

3 Na zona urbana integram-se as estações do Cais do Sodré, Santos, Alcântara-Mar, Junqueira, Belém, Bom Sucesso e Pedrouços. Já a zona rural conta com as estações de Algés, Dafundo, Cruz Quebrada, Caxias, Paço de Arcos, Santo Amaro, Oeiras, Carcavelos, Parede, Cai-Água, São João do Estoril, Estoril, Monte Estoril e Cascais.

4 Não se pode descurar que, no período em estudo, a linha de Cascais já se encontrava modernizada. Em 1926 esta foi electrificada, abandonando a anterior tracção a vapor e constituindo a primeira via-férrea portuguesa a ser dotada de tal símbolo de progresso, com um distanciamento de 30 anos face à seguinte via a ser modernizada, a linha de Sintra. Este empreendimento teve como mentor o empresário Fausto Cardoso de Figueiredo (1880-1950), pertencente tanto aos altos cargos da Companhia Real dos Caminhos de Ferro Portugueses, como sendo um dos sócios principais da Sociedade Estoril, empresa à qual a Companhia concessionou, pelo prazo de 50 anos, a electrificação e exploração do caminho-de-ferro de Cascais, por contrato assinado em Agosto de 1918.

5 A análise só foi feita para o período de 29 anos, entre 1911 e 1940, pois só existem dados da população de facto ao nível da povoação para estes dois últimos anos. Considerou-se como hipótese extrapolar os dados para o período anterior a 1911. Contudo, chegou-se à conclusão de que os cálculos obtidos reflectiriam a presença de uma linha de caminho-de-ferro que, então, ainda não tinha sido construída.

Tendo-se extraído os dados da população de facto de cada um dos lugares da zona suburbana e rural (dos concelhos de Oeiras e Cascais na divisão administrativa de 1940) seleccionaram-se aqueles que, em 1911, possuíam mais de 100 habitantes, calculando-se a respectiva Taxa de Crescimento Anual Médio (TCAM), de forma a caracterizar a sua evolução durante os 29 anos intermédios. Como já foi referido, deve-se considerar que, no período em estudo, foi electrificada a linha de Cascais, tornando a área costeira mais atractiva, uma vez que as viagens eram muito mais rápidas, mais baratas e mais cómodas. Assim, um dos 
O crescimento dos centros de povoamento constitui uma temática pouco estudada, não só no que concerne à linha que liga a Cascais, como a outros espaços suburbanos e rurais das cidades portuguesas, motivo pelo qual existem algumas questões às quais se pretende responder. Contudo, antes de passar a essa problematização, cabe fazer uma introdução geral onde são invocadas as mutações urbanas nas centúrias de Oitocentos e Novecentos, no seu quadrante nacional e especificando o caso da cidade de Lisboa.

Feito este «preâmbulo» e partindo do princípio de que existe uma relação entre a evolução da população de facto nas povoações servidas pelo caminho-de-ferro e a presença deste meio de transporte, visa-se verificar se o caminho-de-ferro promoveu a concentração populacional na zona interior, na faixa litoral, ou seja, junto ao espaço por ele servido, ou em ambos os locais. Desta forma, pode-se atestar, ou não, a existência de um processo de suburbanização na circunvalação férrea à cidade em direcção ao seu Oeste ribeirinho.

De seguida, cabe levar a cabo uma análise micro-espacial, que passa pela verificação das povoações de destaque, ou seja, aquelas cuja relação anteriormente estabelecida era mais forte e quais as características desses mesmos locais - já tinham, ou não, algum relevo pelas actividades neles implementadas, as quais poderiam ser um atractivo à concentração populacional pré-existente? Tal serve de ponto de partida para verificar se o crescimento da população ao longo da faixa costeira teve um carácter contínuo ou descontínuo.

\section{As mutações urbanas dos séculos XIX e XX}

O crescimento urbano português foi lento, por comparação com a restante Europa. Tal está relacionado com o fraco desenvolvimento económico nacional, na primeira metade de Oitocentos, e com o débil crescimento da indústria, que não estimulou a concentração populacional em núcleos

factores que terá estimulado o aumento da população de facto nas povoações analisadas não será, apenas, a presença do caminho-de-ferro, mas também a sua modernização. Para a análise e representação dos dados foi utilizado um Sistema de Informação Geográfico (SIG). 
urbanos. Por outro lado, o peso da população urbana encontrava-se associado às duas maiores cidades portuguesas, Lisboa e Porto. "Essa escassa urbanização, polarizada entre Lisboa e Porto, pouco se altera desde o princípio da centúria (XIX) e indica o desfasamento do País no contexto europeu. Apesar da recuperação em finais do século, este contínua a ser mais um País de vilas e grandes aldeias do que de verdadeiras cidades". ${ }^{6}$ Não se esqueça que, todavia, no contexto europeu, as cidades de Lisboa e Porto apresentavam dimensões médias.

"A taxa de urbanização da Europa (excluindo a Rússia) evoluiu drasticamente dos $19 \%$ em 1850 para os $48 \%$ em 1930. No caso de Portugal, (...) os valores eram consideravelmente mais baixos, cerca de $13 \%$ em 1864 e 24\% em 1930 (...). Sabendo-se que existe uma relação entre a taxa de urbanização e a evolução da riqueza nacional, este resultado é um sinal claro das dificuldades de modernização económica e social do país"? Neste contexto, o peso de Lisboa na população urbana, em 1864, correspondia a $37 \%$ e a do Porto a $17 \%$, enquanto, em 1930, o valor da primeira cidade cresce pouco, para os $39 \%$ e, o da segunda cidade diminui, para os $15,33 \%$. Registe-se, desde as primeiras décadas do século XX, o crescimento populacional significativo dos núcleos urbanos de média dimensão (entre 10000 e 40000 habitantes).

A partir do século XIX deu-se também uma transformação interna nas cidades, que pode ser dividida em três momentos estruturantes: “(...) o núcleo de povoamento inicial [«centro/núcleo histórico»], que no último quartel de Oitocentos perde a liderança do crescimento urbano; uma zona intermédia, que se afirma como o principal receptáculo de população durante o período do apogeu populacional da cidade dos anos 1930 a 1960 [primeira «coroa circular» e outras periferias]; e, por fim, as áreas de limite urbano (...)". ${ }^{8}$ Desta forma, por volta de 1890 , emergiram os centros de

6 RODRIGUES, Teresa - Nascer e morrer na Lisboa Oitocentista. Migrações, mortalidade e desenvolvimento. Lisboa: Edições Cosmo, 1995, p. 45-46; PINHEIRO, Magda (ed.) - Cidade e Metrópole. Centralidades e Marginalidades. Oeiras: Celta Editora, 2001, p. 7; SILVA, Álvaro Ferreira da - A evolução da rede urbana portuguesa (1801-1940). Análise Social, vol. XXXII (143-1944) (1997) 786-789.

7 SILVEIRA, Luís (ed.) - Caminhos de ferro, população e desigualdades territoriais em Portugal, 1801-1930. Ler História. 61 (2011) 21.

8 PINHEIRO, Magda (ed.) - Cidade e Metrópole..., cit., p. 7. 
povoamento exteriores às duas grandes cidades, que atraíram população nos anos posteriores e se revelaram determinantes no contexto do crescimento demográfico dos lugares circundantes às mesmas. Tal motivou uma outra alteração no equilíbrio do sistema urbano que, iniciando-se em 1890, só se consolidou nos anos 60-80 do século XX, relacionada com o processo de metropolização. ${ }^{9}$

Vejamos como tal se processou na cidade de Lisboa, que sempre constituiu um polo de concentração da população no contexto nacional. Nela vários factores sustentaram tais mutações de entre os quais se destaca, indo ao encontro do presente estudo, a construção da rede férrea, na segunda metade de Oitocentos, que distinguiu a capital do contexto nacional, ao que se deve associar o seu porto, local de entrada na Europa e saída para a América. ${ }^{10}$ Já o Inquérito Industrial de 1881 retratou a nova realidade económica portuguesa, fundada no sector industrial e intensificada a partir do mesmo momento. ${ }^{11}$

Antes do terramoto de 1755, a população lisboeta concentrava-se no núcleo histórico junto ao Tejo, na actual Baixa Pombalina (freguesias de Conceição Nova, Santa Justa, Mártires, São Julião e São Nicolau). ${ }^{12}$ A partir da reconstrução da capital, acelerou-se "(...) o processo de expansão urbana para a zona dos planaltos ao longo do rio (Santos e Belém) e sobretudo para o interior, incluindo a Penha de França, o Campo de Santa Clara e também o Rato, Campolide e o Campo Grande". ${ }^{13}$

Desde meados de Oitocentos, deu-se uma saturação fruto do aumento da população residente no centro histórico. Acresceu a construção da estrada da circunvalação (1852), delimitando o futuro crescimento de Lisboa e facilitando a ocupação demográfica da periferia. Esta exteriorização

9 SILVA, Álvaro Ferreira da - A evolução da rede..., cit., p. 810.

${ }^{10}$ SILVA, Álvaro Ferreira da - A evolução da rede..., cit., p. 810.

${ }^{11}$ RODRIGUES, Teresa - Nascer e morrer..., cit., p. 43.

${ }^{12}$ FERREIRA, Vítor Matias - A cidade de Lisboa: de capital do império a centro da metrópole. Lisboa: Publicações Dom Quixote, 1987, p. 85 e 110.

${ }^{13}$ PINHEIRO, Magda (ed.) - Cidade e Metrópole..., cit., p. 9. 
urbana foi acompanhada por alterações administrativas, fazendo crescer as dimensões da capital e aumentando as freguesias e bairros. ${ }^{14}$

Assim, a partir de 1878, quando já circulavam as carreiras de americanos (que, aliadas à estrada da circunvalação, colmatavam os problemas de circulação interna), Lisboa cresceu para a considerada primeira «coroa circular», o que foi favorecido pela substituição do Passeio Público pela Avenida de Liberdade, inaugurada a 4 de Agosto de 1879, e acompanhando dois eixos com elevado peso demográfico: das Avenidas Novas para o Campo Grande e da Avenida Almirante Reis para o Lumiar. Este aumento demográfico resultou, sobretudo, de “(...) um crescimento de «conquista» de populações não-naturais daquele concelho, oriundas, por isso, de «meios rurais» situados, na generalidade, no próximo exterior ao distrito de Lisboa". ${ }^{15}$

Indo ao encontro do espaço ribeirinho em análise, mas ainda dentro do limite administrativo da cidade, pode-se considerar um outro eixo de

${ }^{14}$ A estrada da circunvalação - tendo como limites a Oeste a Rua Maria Pia, a Norte a Avenida Duque de Ávila e, a Este, a Rua Morais Soares - motivou a ocupação demográfica da zona norte de Lisboa. Esta foi responsável pela reformulação do limite da cidade (1885), passando a capital a ser composta por 6500 hectares e correspondendo ao seguinte espaço: "Partindo da actual pelo vale de Chelas, vá entroncar com a estrada militar até Benfica, e abrangendo esta povoação, e percorrendo a margem esquerda da ribeira de Algés, termine na ponte do mesmo nome" (VENTURA, António (ed.) - História da Companhia Carris de Ferro de Lisboa. Lisboa: Companhia Carris de Ferro de Lisboa / Academia Portuguesa da História, 2006, p. 57). Em 1886, além de parte das freguesias que havia perdido para os concelhos de Belém e Olivais, Lisboa anexou as freguesias de Camarate e Sacavém, passando a capital a ter uma dimensão de 8244 hectares. Porém, esta vasta extensão não significava que todo o espaço estivesse urbanizado - «expansão urbana sem urbanização». ALVES, Daniel - Evolução das freguesias da cidade de Lisboa ao longo do século XIX. SIGMA - Sistema de Informação Geográfica e Modelação de Dados Aplicados à História de Portugal (2004), p. 2 (http://www2.fcsh.unl.pt/deps/historia/docs/lisboa.pdf, consultado em 2013.05.29); FERREIRA, Jaime - Um século de moagem em Portugal, de 1821 a 1920. Das fábricas às Companhias e aos grupos de Portugal e Colónias e da Sociedade Industrial Aliança in ALVES, Jorge Fernandes (coord.) - A indústria portuguense em perspectiva histórica: actas do Colóquio. Porto: Centro Leonardo Coimbra / Faculdade de Letras da Universidade do Porto, s.d., p. 4; FERREIRA, Vítor Matias - A cidade de Lisboa ..., cit., p. 89 e 110; PINHEIRO, Magda (ed.) - Cidade e Metrópole ..., cit., p. 8; RODRIGUES, Teresa - Nascer e morrer ..., cit., p. 50-51; VENTURA, António (ed.) - História da Companhia ..., cit., p. 58.

${ }^{15}$ FERREIRA, Vítor Matias - A cidade de Lisboa ..., cit., p. 95 e 99-100; PINHEIRO, Magda (ed.) - Cidade e Metrópole ..., cit., p. 9; PINHEIRO, Magda - Biografia de Lisboa. Lisboa: A Esfera dos Livros, 2011, p. 250. 
crescimento, as freguesias de Alcântara e Belém, ocupadas por indústrias e comércio dependentes do porto de Lisboa. ${ }^{16}$

Correspondendo ao que pode ser considerada a segunda «coroa circular», por um maior afastamento ao centro histórico, deu-se a expansão da cidade noutros eixos. Tal resultou da saturação do centro e da primeira coroa, bem como do elevado custo do solo para urbanização. Neste grupo integra-se o concelho de Oeiras, bem como a restante marginal, onde se destacam as povoações de Algés, Paço de Arcos, Oeiras, Parede, Estoril e Cascais, que já tinham uma população de facto significativa estando, igualmente, associadas a uma ou mais actividades económicas, como se verá. Acrescente-se o eixo Benfica-Amadora-Queluz-Sintra, acompanhando a linha de Sintra, construída em 1887 e electrificada em 1956; Loures; Vila Franca de Xira-Arruda dos Vinhos; Sobral de Monte Agraço; bem como povoações da margem sul do Tejo, nomeadamente, o Barreiro e Montijo com o seu elevado atractivo industrial.

Este crescimento das povoações periféricas é o prenúncio da Área Metropolitana de Lisboa, que se forma nos anos 70 do século XX, assistindo-se a uma mutação de funções: a zona central deixa de ter um cariz residencial para predominarem as funções administrativas e comerciais, enquanto as povoações periféricas passam a constituir zonas dormitório, ainda que

${ }^{16}$ Teresa-Nascer e morrer..., cit., p. 54. Por exemplo, em Alcântara localizavam-se a Companhia de Fiação e Tecidos Lisbonense e a de Fiação e Tecidos do Alto de Santo Amaro, a Fábrica da Cabrinha, a Fábrica de Louça de Lopes e C. ${ }^{a}$ e, a partir de 1898, a Companhia União Fabril. Nesta freguesia, ao trabalho industrial deve-se somar uma ocupação residencial associada ao operariado e à pequena burguesia industrial, como existia, por exemplo, no Bairro do Calvário, situado entre a Junqueira e Alcântara, o que levou a um duplicar da população entre 1890-1950. Contrastando, e remetendo para um estrato social mais elevado, a elite ocupava Belém, entre a Junqueira e o Restelo, espaço que quase triplicou a sua população no mesmo hiato cronológico. António Ventura refere que os empresários pretendiam que os trabalhadores habitassem junto às fábricas, concedendo-lhes subsídios para pagarem as suas rendas. Assim, as habitações eram edificadas nas zonas marginais da cidade, como o vale de Alcântara, tendo a Companhia de Fiação de Tecidos Lisbonense sido pioneira neste tipo de iniciativa. VENTURA, António (ed.) - História da Companhia ..., cit., p. 77 e 85. Sobre Alcântara, refira-se VIDAL, Frédéric - Les habitants d'Alcântara. Histoire sociale d'un quartier de Lisbonne au début du XXe siècle. Lyon: s.n., 2003. FERREIRA, Vítor Matias A cidade de Lisboa ..., cit., p. 112; PINHEIRO, Magda (ed.) - Cidade e Metrópole..., cit., p. 66; VENTURA, António (ed.) - História da Companhia ..., cit., p. 63, 72, 77 e 85. 
espacialmente descontínuas, desenhando o que Vítor Matias Ferreira designa de «manchas d'óleo». ${ }^{17}$

É ainda de referir que, tanto no caso do desenvolvimento das povoações em torno de Lisboa, como do Porto, aquelas que apresentavam um maior crescimento populacional são as que possuíam maior e melhor acesso aos meios de transporte. Numa primeira fase, o caminho-de-ferro motivou o rápido e forte crescimento de Lisboa e do Porto, bem como das povoações envolventes. ${ }^{18}$ Também os americanos e os tramways tiveram um papel decisivo, sendo que "(...) acompanharam a expansão dos limites legais da cidade, precedendo nalguns casos a urbanização". ${ }^{19}$ Some-se, já no século XX, o papel do automóvel.

\section{O crescimento das povoações da linha de Cascais (1911-1940)}

Parta-se da ideia historiograficamente aceite e desenvolvida no ponto anterior de uma grande concentração populacional no centro histórico de Lisboa, que motivava um encarecimento do custo do solo, levando à ocupação dos espaços periféricos ainda dentro da cidade e, depois, fora dela, estimulando o desenvolvimento de centros de povoamento, sobretudo, a partir de 1890.

Como já foi referido, um dos eixos de crescimento foi junto à zona ribeirinha, tendo o caminho-de-ferro estimulado e promovido a fixação de habitantes entre Algés e Cascais, sobretudo, nos espaços suburbanos onde já se encontrava estabelecido algum sector de actividade. Neste sentido, quando analisado o tráfego da linha de Cascais, as povoações que emergiam como principais eram Algés, Paço de Arcos, Oeiras, Parede, Estoril e Cascais. ${ }^{20}$

${ }^{17}$ FERREIRA, Vítor Matias - A cidade de Lisboa..., cit., p. 236 e 242.

${ }^{18}$ PINHEIRO, Magda - Cidade e Caminhos de Ferro. Lisboa: Centro de Estudos de História Contemporânea Portuguesa, 2008, p. 46.

${ }^{19}$ PINHEIRO, Magda - Cidade e Caminhos ..., cit., p. 56.

${ }^{20}$ Para esta conclusão foi calculado o tráfego percentual anual de cada estação, fazendo ressaltar aquelas que estavam acima da média (mesmo que o estivessem apenas em um ano). Consultar: PAULINO, Joana - A linha de Cascais ..., cit., p. 99, 102-103 e 106-107. 
Imagem 1 - Crescimento da população de facto nas povoações dos concelhos de Cascais e Oeiras com mais de 100 habitantes

Divisão administrativa de 1940; TCAM (1911-1940) e distância ao caminho-de-ferro (1 quilómetro, 2 quilómetros e 5 quilómetros).

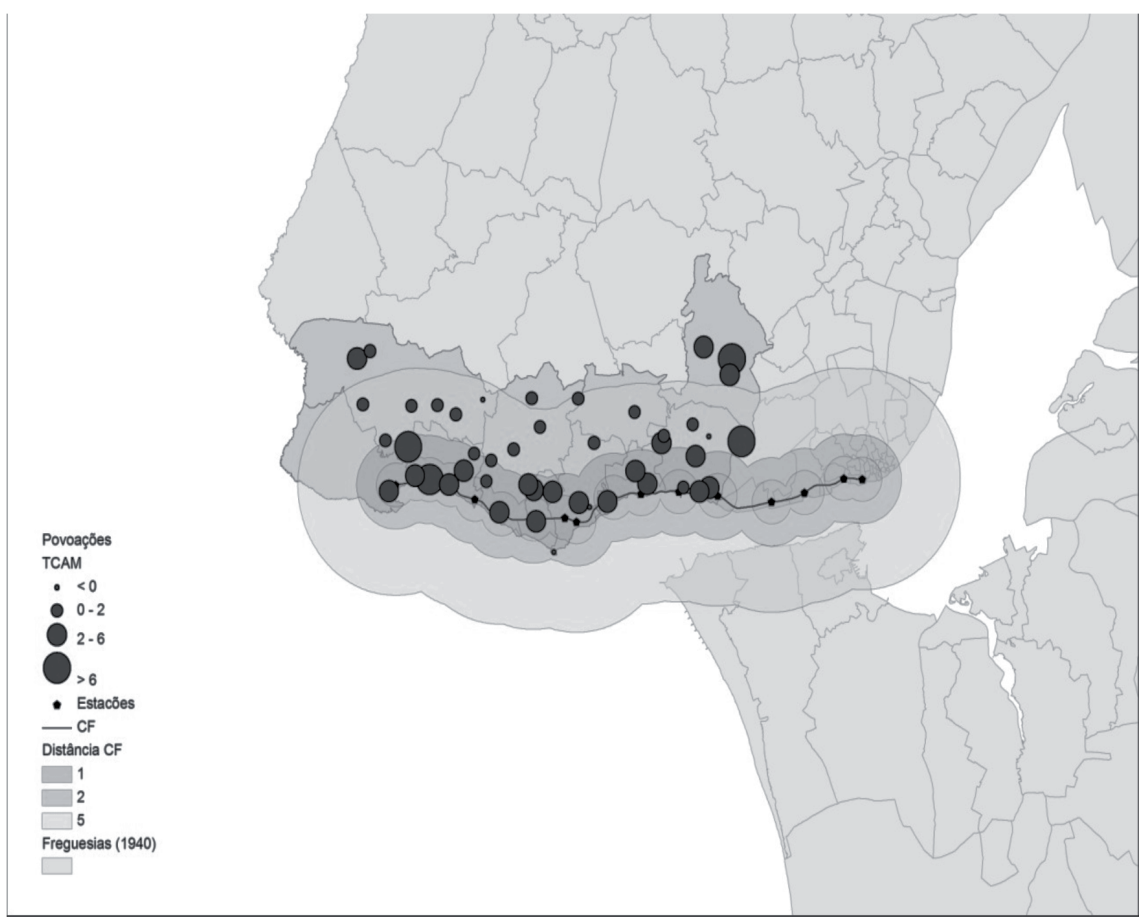

Fonte: Ministério das Finanças - Direcção Geral de Estatística - 4a Repartição Estatística Demográfica-Censo da População de Portugal no $1^{\circ}$ de Dezembro de 1911. Lisboa: Imprensa Nacional, 1913; Instituto NACional DE EstatísticA - VIII Recenseamento geral da população no Continente e Ilhas Adjacentes em 12 de Dezembro de 1940. Lisboa: Imprensa Nacional. 1945.

Vejamos, agora, qual a influência do caminho-de-ferro - este motivou um incremento do povoamento da zona litoral, da zona interior, de ambas ou apenas de uma delas?

Como se pode constatar pela imagem anteriormente apresentada, as povoações com uma Taxa de Crescimento Anual Médio (TCAM) mais elevada correspondem, grosso modo, àquelas que se situam junto ao ramal de Cascais, nomeadamente, a uma distância inferior ou igual a 1 quilómetro, salvo 5 excepções de seguida enunciadas. Desta forma, existe uma relação entre a proximidade a este meio de transporte e o crescimento da população 
de facto nas povoações por ele servidas. Enquanto a TCAM das povoações localizadas no primeiro anel do buffer $(=\mathrm{ou}<1 \mathrm{~km})$ se situa entre os $2-6 \% \mathrm{e}$, para o caso do Estoril, acima dos $6 \%$, conforme nos afastamos da via-férrea, sobretudo, em distâncias superiores a 5 quilómetros, esta tendência tende a dissipar-se, apresentando os lugares uma TCAM inferior a $2 \%$ e, em dois casos particulares (na Outorela e em Manique), emergindo percentagens negativas.

Imagem 2 - Relação entre TCAM (1911-1940) e a distância ao caminho-de-ferro

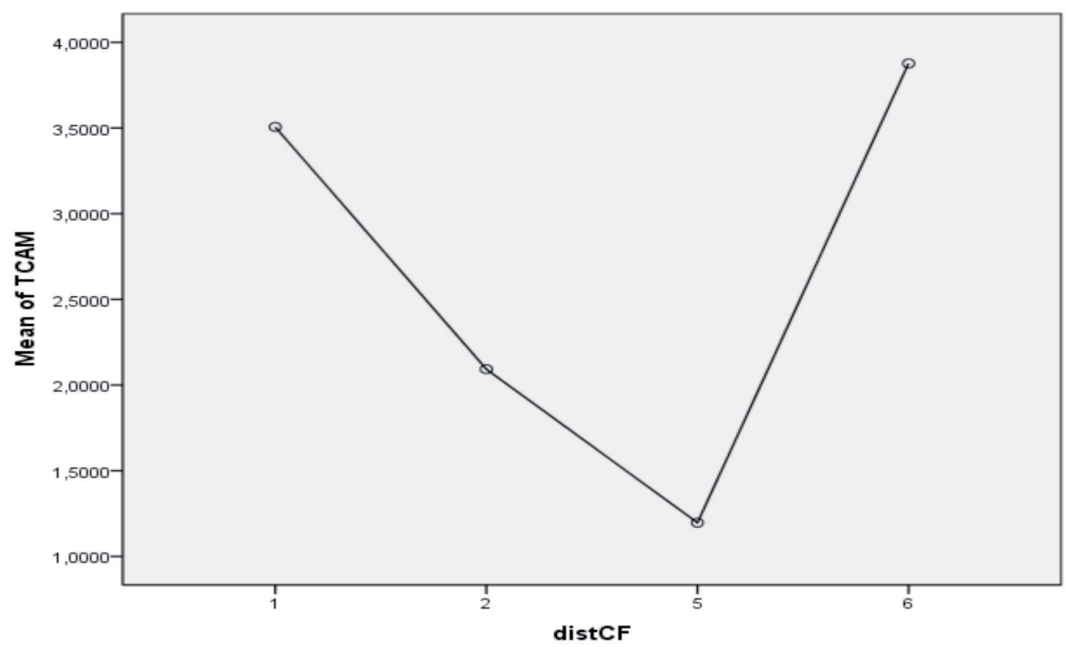

Fonte: Ministério das Finanças - Direcção Geral de Estatística - 4a Repartição Estatística Demográfica-Censo da População de Portugal no $1^{\circ}$ de Dezembro de 1911. Lisboa: Imprensa Nacional, 1913; Instituto Nacional DE Estatística - VIII Recenseamento geral da população no Continente e Ilhas Adjacentes em 12 de Dezembro de 1940. Lisboa: Imprensa Nacional. 1945.

Tabela 1 - Número de povoações para cada classe de distância ao caminho-de-ferro e respectiva média

\begin{tabular}{|c|c|c|}
\hline Classes DistCF & No de Povoações $^{\text {M }}$ & Média \\
\hline 1 & 13 & 3,506 \\
\hline 2 & 10 & 2,092 \\
\hline 5 & 16 & 1,197 \\
\hline 6 & 6 & 3,877 \\
\hline
\end{tabular}

Fonte: Ministério das Finanças - Direcção Geral de Estatística - 4 a Repartição - Estatística Demográfica..., cit.; Instituto Nacional de Estatística - VIII Recenseamento geral..., cit. 
A surpresa surge quando se analisa a mesma taxa no que concerne às povoações com um afastamento igual ou superior a 6 quilómetros: embora constituam um número mais reduzido, de 6 lugares, apresentam um crescimento percentual anual de cerca de $3,88 \%$, suplantando o valor das zonas próximas da linha de Cascais.

Não obstante, os valores apresentados neste último caso podem ser facilmente explicados. Tendo-se adoptado a divisão administrativa de 1940, deve-se ter em conta que o concelho de Oeiras tinha grandes dimensões. Incluíam-se, neste, as povoações da Amadora, Venda Nova e Damaia, cuja elevada TCAM é justificada não pela influência do ramal de Cascais, mas da linha de Sintra, pela qual estas eram directamente atravessadas. Atesta-se, aqui, um processo de suburbanização motivado por esta última via-férrea e que, contrastando com aquele que se processa junto à zona ribeirinha, se dá rumo ao interior. Importava desenvolver-se um novo estudo que se debruçasse sobre o processo de suburbanização à luz destas duas vias ferroviárias. As 3 restantes povoações com uma maior TCAM são a Portela de Carnaxide, Malveira da Serra e Amoreira. Contudo, estes são lugares interiores, com ausência de caminho-de-ferro, pelo que se torna difícil discernir um justificativo para o seu peso.

Paralelamente, assim se justifica que o valor da correlação entre a Taxa de Crescimento Anual Médio e a distância ao caminho-de-ferro, seguindo o método de Pearson, seja de 0,016 , revelando uma fraca relação entre ambos os elementos de análise.

Sabendo que o crescimento junto ao litoral foi mais relevante do que na zona interior, quais as povoações com uma TCAM mais representativa e que, neste sentido, contribuíram para a suburbanização de Lisboa na faixa costeira para Oeste?

Tabela 2- Evolução da população de facto nas principais povoações servidas pela linha de Cascais e respectiva TCAM

\begin{tabular}{|c|c|c|c|}
\hline Povoação & PopFacto1911 & PopFacto1940 & TCAM \\
\hline Algés & 2427 & 7836 & 4,12 \\
\hline Caxias & 579 & 1507 & 3,35 \\
\hline Dafundo & 945 & 2244 & 3,03 \\
\hline Paço de Arcos & 1571 & 3502 & 2,80 \\
\hline
\end{tabular}




\begin{tabular}{|c|c|c|c|}
\hline Povoação & PopFacto1911 & PopFacto1940 & TCAM \\
\hline Oeiras & 1715 & 4011 & 2,97 \\
\hline Parede & 1301 & 4603 & 4,45 \\
\hline Estoril & 298 & 2935 & 8,20 \\
\hline Cascais & 3445 & 7115 & 2,53 \\
\hline
\end{tabular}

Fonte: Ministério das Finanças - Direcção Geral de Estatística - 4 ${ }^{\mathrm{a}}$ Repartição -

Estatística Demográfica ..., cit.; Instituto Nacional de Estatística - VIII Recenseamento geral..., cit.

Em 1895 constatava-se que "de há muito que a área da nossa capital foi alargada até Algés, mas, apesar da população cobrir numa grande intensidade naquela zona, ela conservava-se pouco menos que afastada do coração da capital (...)". ${ }^{21}$ Acompanhando a tendência sentida em 1895, verifica-se que a TCAM das povoações próximas de Algés, nomeadamente, do Dafundo e, embora com uma percentagem mais reduzida, da Cruz Quebrada, é significativa.

A povoação de Algés possui uma das TCAM mais elevadas. Este lugar, no período em análise, quase triplicou o seu peso demográfico, passando de 2427 habitantes (1911) para 7836 (1940). O seu relevo está associado, tal como o de Caxias e do Dafundo, ao facto de se encontrarem no espaço imediatamente limítrofe à cidade de Lisboa. Qualquer uma destas 3 povoações pode-se considerar um subúrbio da capital, uma vez que desenvolvem uma relação funcional e de dependência face a esta. Assiste-se, assim, a uma ocupação de lugares que não estavam associados à presença de indústrias fabris e manufactureiras, constituindo zonas residenciais limítrofes à cidade de Lisboa. Tal é verificado pelo trânsito de passageiros, a partir do qual se nota esta relação entre a capital e Algés, bem como entre a primeira, Dafundo e Cruz Quebrada, ainda que com menor importância por comparação à primeira povoação. ${ }^{22}$

Assim, de Algés à Cruz Quebrada pode-se atestar uma ocupação espacial com um carácter contínuo, sem ruptura desde o núcleo da grande cidade. Tal pode-se encontrar relacionado não só com a presença do caminho-de-ferro, como com a extensão do tramway eléctrico à Cruz Quebrada,

${ }^{21}$ COSTA, Leonildo de Mendonça - Gazeta dos Caminhos de Ferro, 185 (1895) 260.

${ }^{22}$ PAULINO, Joana - A linha de Cascais..., cit., p. 91-107. 
em 1911. ${ }^{23}$ O espaço entre Algés e a Cruz Quebrada estava a contribuir para o processo de suburbanização, pela ocupação residencial deste segmento, o que justificava o investimento nesta modernização e atesta a existência do tráfego da periferia urbana para o seu interior.

Considere-se que o crescimento da população de facto, entre 1911-1940, no espaço compreendido entre a Cruz Quebrada e Cascais, se deu em povoações que já eram dotadas de algum desenvolvimento, como Paço de Arcos, Oeiras, Parede, Estoril e Cascais. Estas contribuiram, no que concerne ao tráfego de passageiros, para a existência de deslocações no seio do espaço rural, podendo-se verificar o seu carácter pendular, nomeadamente, de movimentações menores ocorridas entre as estações mais próximas. ${ }^{24}$

Quanto a Paço de Arcos e Oeiras, embora possuam umas das TCAM mais reduzidas, com um crescimento de 1571 habitantes (1911) para 3502 (1940) e de 1715 (1911) para 4011 (1940), respectivamente, de acordo com o Inquérito Industrial de 1881, ambas as povoações estavam associadas ao sector extrativo. Segundo a mesma fonte, em Paço de Arcos existiam pedreiras, cuja "(...) maior quantidade de pedra explorada para cantaria é destinada ao revestimento de muros de cais, especialmente das obras do porto de Lisboa, onde ela é empregada largamente (...)". ${ }^{25}$ Por sua vez, na povoação de Oeiras, existiam pedreiras exploradas por Hersent e Genelioux, cuja extracção era destinada ao porto de Lisboa e indo o calcário para os Açores. Possivelmente, aquando da conclusão das obras do porto de Lisboa o sector extrativo poderá ter perdido a sua importância, justificando a baixa TCAM. É ainda invocado que estas duas povoações eram dotadas de um desenvolvimento industrial significativo, o que ajudou a manter um crescimento da população de facto sustentado. ${ }^{26}$ Por outro lado, não se deve descurar a importância de Paço de Arcos nas práticas de veraneio, sobretudo, ao Domingo. ${ }^{27}$ Ainda que esta seja uma povoação atractiva para a prática de

${ }^{23}$ PINHEIRO, Magda - Impacto da construção ferroviária sobre a cidade de Lisboa. S.l.: s.n, s.d., p. 12.

${ }^{24}$ Ver PAULINO, Joana - A linha de Cascais..., cit., p. 91-107.

${ }^{25}$ Inquérito Industrial de 1881: inquérito directo, Vol. I. Lisboa: Imprensa Nacional, 1881-1883, p. 235.

${ }^{26}$ Inquérito Industrial..., cit., p. 235.

${ }^{27}$ COLAÇO, Branca de Gonta (ed.) - Memórias da Linha de Cascais. Lisboa: Parceria António Maria Vieira, 1999, p. 35. 
banhos e, sendo referido que apenas o era num dia, associam-se movimentos pendulares, em detrimento de uma ocupação absoluta do espaço.

Na povoação da Parede, cuja TCAM é de 4,45, a mais elevada a seguir ao Estoril, verifica-se mais do que um triplicar da população nos 29 anos de análise. Neste lugar, a estação ferroviária tinha sido construída quase exclusivamente para o serviço das pedreiras. Simultaneamente, "esta localidade tem uma das estâncias balneares mais afamadas do País. O microclima suave e a elevada concentração de iodo na sua praia converteram esta freguesia do concelho de Cascais num lugar de excelência para o tratamento de doenças ósseas", estando este espaço associado a um veraneio medicinal, terapêutico e cientificamente certificado. ${ }^{28}$ Foi por este motivo que aí se fixou o Sanatório de Santa Ana (1904) considerado, à data, um dos melhores hospitais ortopédicos da Europa. ${ }^{29}$ Segundo Pedro Martins, por volta de 1930-1940, a Parede era, fundamentalmente, uma área residencial, considerando a existência de poucos hotéis. ${ }^{30}$

Este atractivo medicinal, que se deve associar ao sector económico emergente, o turismo, também justifica o peso de São João do Estoril, Estoril e Monte Estoril. A presença de estâncias termais nestas zonas, dotadas de edifícios de lazer, como casinos e casas de jogo de fortuna e azar, tornou-as atractivas enquanto espaços residenciais. Neste contexto, ressalta o crescimento do Estoril, sobretudo, a partir da construção do projecto cosmopolita e internacional de Fausto de Figueiredo, o Parque Estoril. A sua TCAM é a mais elevada havendo um aumento de $8,20 \%$ por ano, que corresponde a uma transição de apenas 298 (1911) pessoas para 2935 (1940), o que é explicado pelo loteamento dos terrenos junto ao Parque Estoril, constituindo este um «chamariz» à fixação de população. Por outro lado, considere-se que as pessoas que trabalhavam no Parque e nas infraestruturas por ele desenvolvidas residiam neste espaço ou nas povoações próximas. Neste contexto, o Estoril destacava-se enquanto local de lazer,

${ }^{28}$ SILVA, José Ribeiro da (ed.) - Os comboios em Portugal. Do vapor à electricidade, vol. IV. Lisboa: Terramar, 2008, p. 229.

${ }^{29}$ SILVA, José Ribeiro da (ed.) - Os comboios..., cit., p. 229; MARTINS, Pedro Contributos para uma história do ir à praia em Portugal. Lisboa: F.C.S.H.-U.N.L., 2011, p. 37-39.

${ }^{30}$ MARTINS, Pedro - Contributos para ..., cit., p. 44-45. 
com um turismo vocacionado para o cosmopolitismo e de cariz internacional, tendo o projecto de Fausto de Figueiredo incrementado a urbanização em seu torno, a qual foi, igualmente incentivada pela electrificação do ramal de Cascais. ${ }^{31}$

Quanto a Cascais, esta era uma vila piscatória, cuja importância não remonta à presença do caminho-de-ferro, ainda que este a tenha dinamizado. $\mathrm{O}$ destaque atribuído à mesma está relacionado com a prática turística e, com ela, ao gosto pelos banhos de mar e veraneio. Tal justifica que, em 1911 já existissem 3445 habitantes, o maior valor de todas as povoações analisadas. Contudo, o seu crescimento não foi tão significativo como as restantes contabilizando-se, em 1940, 7115 habitantes. Ainda que continuasse a ser das povoações com um maior número de pessoas, o seu crescimento demográfico nestes 29 anos não foi tão significativo como noutras localidades.

Pode-se, assim, atestar um crescimento do espaço suburbano à cidade de Lisboa e uma tendência para delimitação da zona metropolitana a Oeste da capital e junto à zona ribeirinha. Este processo de suburbanização, ainda que na mesma faixa costeira, realizou-se de acordo com dois padrões distintos. Por um lado, a população ocupou os lugares imediatamente limítrofes à cidade, como Algés, Dafundo e Cruz Quebrada. Por outro, emerge um outro tipo de ocupação do espaço, extremamente vinculado à presença do caminho-de-ferro e à existência de aglomerados cujo desenvolvimento era notório pela existência de determinados sectores de actividade (fosse pela extracção ou pelo turismo/práticas de vilegiatura). Estão incluídos neste grupo Paço de Arcos, Oeiras, Parede, São João do Estoril, Estoril, Monte Estoril e Cascais. Como se constata pelo afastamento entre cada uma destas povoações, pode-se concluir que a sua ocupação estimulou uma ruptura com a fixação contínua que se tinha processado até à Cruz Quebrada, sendo indissociável da proximidade a pontos de trabalho e ao caminho-de-ferro. Estas povoações, contrastando com Algés, Dafundo e Cruz Quebrada, não tinham uma relação funcional e dependente da capital.

${ }^{31}$ MARTINS, Pedro - Contributos para ..., cit., p. 45-47. 


\section{Conclusão}

Perante a falta de estudos sobre a linha de Cascais e considerando a actual hipótese de encerramento da mesma, é relevante estudar não só a sua construção e modernização, como também os seus reflexos na população por ela servida.

A análise concretizada permitiu verificar que o ramal de Cascais constituiu, efectivamente, um dos eixos de expansão e crescimento da cidade de Lisboa para fora de si mesma. Num momento inicial, e correspondendo ao seu fito de construção, este caminho-de-ferro revelou-se crucial para as deslocações da cidade para o espaço rural, servido por praias. Esta tendência alterou-se com a abertura da estação do Cais do Sodré (1895), que atribuiu um pendor urbano ao tráfego nesta via-férrea. Inaugurado o eléctrico, como meio concorrencial (1901), a linha de Cascais retomou a importância das suas ligações de, para e dentro da área rural, o que se encontra relacionado com o desenvolvimento dos centros de povoamento por ela servidos, cuja população de facto cresce de forma significativa. Assim, pode-se integrar o espaço marginal atravessado pelo ramal de Cascais no processo de suburbanização da cidade de Lisboa.

A utilização de um Sistema de Informação Geográfico permitiu atestar o crescimento da população de facto com particular concentração junto ao caminho-de-ferro e, com ele, acompanhando a zona litoral. Entre 1911-1940, deu-se um processo de suburbanização a Oeste de Lisboa, que se fez sentir nas povoações limítrofes à grande cidade, nomeadamente, Algés, Dafundo e Cruz Quebrada, com uma ocupação contínua do espaço, ainda que estes lugares fossem, essencialmente, dormitórios, estando dependentes da capital. Neles não se pode invocar apenas a influência da via-férrea, mas também do eléctrico, com terminus na Cruz Quebrada.

Por sua vez, noutras povoações servidas pelo caminho-de-ferro, como são o caso de Paço de Arcos, Oeiras, Parede, Estoril, e Cascais, verificou-se um aumento da ocupação demográfica do espaço, a qual já tinha algum relevo, ao que se deve associar não só o papel da via-férrea, como também o facto de a elas estar associado determinado sector de actividade, fosse ele primário, como a extracção, ou terciário, como o turismo. Alguns anos mais tarde estas povoações viriam a constituir a Área Metropolitana de Lisboa. 
É um facto que esta via-férrea ajudou na promoção da suburbanização de Lisboa. Há que fazê-la perdurar na memória, emergindo o presente estudo como um contributo tanto para a história dos caminhos-de-ferro, como para a história regional e social.

\section{Bibliografia}

\section{Fontes}

\section{Arquivos}

Arquivo Histórico e Fotográfico da Comboios de Portugal

GFundos: Fundos Modernos; Fundo: CP; Secção: Administração;

SSecção: Secretaria-Geral; Série: Contratos e Documentação Afim;

SSérie: Linha de Cascais-Sociedade Estoril, caixas 484 e 485.

Arquivo da Fundação Museu Nacional Ferroviário - Armando Ginestal Machado

Disponível em: http://www.fmnf.pt/arquivo - PT/FMNF/DGCF-

DFECF/8-Série - Linha de Cascais - 1874-1940.

Instituto Nacional de Estatística

\section{Fontes impressas}

Inquérito Industrial de 1881: inquérito directo, Vol. I. Lisboa: Imprensa Nacional, 1881-1883.

INSTITUTO NACIONAL DE ESTATÍSTICA - VIII Recenseamento geral da população no Continente e Ilhas Adjacentes em 12 de Dezembro de 1940. Lisboa: Imprensa Nacional, 1945.

MINISTÉRIO DAS FINANÇAS - DIRECÇÃO GERAL DE ESTATÍSTICA - $4^{\mathrm{a}}$ REPARTIÇÃO - Estatística Demográfica - Censo da População de Portugal no $1^{\circ}$ de Dezembro de 1911. Lisboa: Imprensa Nacional, 1913.

\section{Periódicos}

COSTA, Leonildo de Mendonça - Gazeta dos Caminhos de Ferro, 185 (1895). 


\section{Estudos}

ALVES, Daniel - Evolução das freguesias da cidade de Lisboa ao longo do século XIX. SIGMA - Sistema de Informação Geográfica e Modelação de Dados Aplicados à História de Portugal (2004), (http://www2.fcsh. unl.pt/deps/historia/docs/lisboa.pdf, consultado em 2013.05.29).

COLAÇO, Branca de Gonta (ed.) - Memórias da Linha de Cascais. Lisboa: Parceria António Maria Vieira, 1999.

FERREIRA, Jaime - Um século de moagem em Portugal, de 1821 a 1920. Das fábricas às Companhias e aos grupos de Portugal e Colónias e da Sociedade Industrial Aliança in ALVES, Jorge Fernandes (coord.) A indústria portuense em perspectiva histórica: actas do Colóquio. Porto: Centro Leonardo Coimbra / Faculdade de Letras da Universidade do Porto, s.d., p. 271-283.

FERREIRA, Vítor Matias - A cidade de Lisboa: de capital do império a centro da metrópole. Lisboa: Publicações Dom Quixote, 1987.

MARTINS, Pedro - Contributos para uma história do ir à praia em Portugal. Lisboa: F.C.S.H.-U.N.L., 2011.

PAULINO, Joana - A linha de Cascais: construção e modernização. Reflexos no turismo e no processo de suburbanização da cidade de Lisboa. Lisboa: F.C.S.H.-U.N.L., 2013.

PINHEIRO, Magda - Biografia de Lisboa. Lisboa: A Esfera dos Livros, 2011. PINHEIRO, Magda - Cidade de Caminhos de Ferro. Lisboa: Centro de Estudos de História Contemporânea Portuguesa, 2008.

PINHEIRO, Magda (ed.) - Cidade e Metrópole. Centralidades e Marginalidades. Oeiras: Celta Editora, 2001.

PINHEIRO, Magda - Impacto da construção ferroviária sobre a cidade de Lisboa. S.l.: s.n, s.d.

RODRIGUES, Teresa - Nascer e morrer na Lisboa Oitocentista. Migrações, mortalidade e desenvolvimento. Lisboa: Edições Cosmo, 1995.

SILVA, Álvaro Ferreira da - A evolução da rede urbana portuguesa (1801-1940). Análise Social, vol. XXXII (143-1944) (1997).

SILVA, José Ribeiro da (ed.) - Os comboios em Portugal. Do vapor à electricidade, vol. IV. Lisboa: Terramar, 2008.

SILVEIRA, Luís (et. al.) - Caminhos de ferro, população e desigualdades territoriais em Portugal, 1801-1930. Ler História. 61 (2011) 7-37. 
VENTURA, António (ed.) - História da Companhia Carris de Ferro de Lisboa. Lisboa: Companhia Carris de Ferro de Lisboa / Academia Portuguesa da História, 2006.

VIDAL, Frédéric - Les habitants d'Alcântara. Histoire sociale d'un quartier de Lisbonne au début du XXe siècle. Lyon: s.n., 2003. 